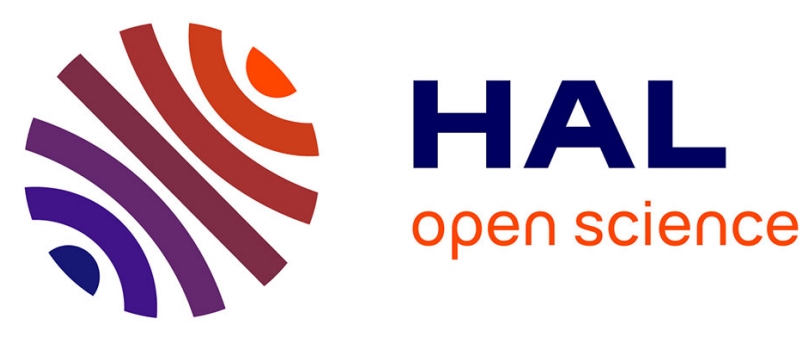

\title{
A novel distributed supplementary control of Multi-Terminal VSC-HVDC grids for rotor angle stability enhancement of AC/DC systems
}

Juan Carlos Gonzalez Torres, Gilney Damm, Valentin Costan, Abdelkrim

Benchaid, Françoise Lamnabhi-Lagarrigue

\section{To cite this version:}

Juan Carlos Gonzalez Torres, Gilney Damm, Valentin Costan, Abdelkrim Benchaid, Françoise Lamnabhi-Lagarrigue. A novel distributed supplementary control of Multi-Terminal VSC-HVDC grids for rotor angle stability enhancement of AC/DC systems. IEEE Transactions on Power Systems, 2021, 36 (1), 12p. 10.1109/TPWRS.2020.3030538 . hal-03498790

\section{HAL Id: hal-03498790 \\ https://hal.science/hal-03498790}

Submitted on 21 Dec 2021

HAL is a multi-disciplinary open access archive for the deposit and dissemination of scientific research documents, whether they are published or not. The documents may come from teaching and research institutions in France or abroad, or from public or private research centers.
L'archive ouverte pluridisciplinaire HAL, est destinée au dépôt et à la diffusion de documents scientifiques de niveau recherche, publiés ou non, émanant des établissements d'enseignement et de recherche français ou étrangers, des laboratoires publics ou privés. 


\title{
A novel distributed supplementary control of Multi-Terminal VSC-HVDC grids for rotor angle stability enhancement of AC/DC systems
}

\author{
Juan Carlos Gonzalez-Torres, Gilney Damm, Valentin Costan, Abdelkrim Benchaib, and \\ Françoise Lamnabhi-Lagarrigue
}

\begin{abstract}
This paper presents a distributed supplementary control for embedded Multi-Terminal VSC-HVDC (MTDC) grids to enhance the transient stability of the surrounding $\mathrm{AC}$ grid. Firstly, the need of supplementary controllers for embedded MTDC grids is demonstrated via the study of the Transient Energy Functions (TEF) of a simple hybrid AC/DC power system. Then, the proposed control structure is presented. This control aims to enhance the angle stability of the surrounding AC system via the modulation of the active power references of the converters. The objective of the control is to enhance AC transient stability while keeping the power balance of the DC grid even if converters reach their active power limits. The proposed control uses frequency and angle measurements at the Point of Common Coupling (PCC) of the converters. The idea behind the proposed strategy is to match the control actions and limits of each pair $(i, j)$ of converters. If converter $i$ modulates its power, converter $j$ modulates the same amount of power in the opposite direction. The concept of virtual links is used in this paper to represent this matching. Finally, the proposed controller is tested on a modified version of the IEEE 39 bus system using EMT simulations.
\end{abstract}

Index Terms-Hybrid AC/DC Transmission Grids, Transient stability, Multi-terminal DC grids, Wide Area Control System.

\section{INTRODUCTION}

C URRENT trends in power systems, such as integration of renewable energies and the development of an electricity market place, have led to accelerated changes in their structure and operation. To deal with the related current and upcoming challenges, the necessity to reinforce the transmission systems is evident. In this context, High-Voltage Direct Current (HVDC), especially in multi-terminal (MTDC) configuration, has proven to be the most adapted technology for the reinforcement and upgrading of transmission systems. However, if their potential is to be fully exploited, MTDC grids need to be used not only for transmission purposes, but also to improve the stability of the network to which they are connected. It has been recognized that advanced functionalities of HVDC systems are essential for the efficient and secure operation of the grid [1]. This article proposes mechanisms via which MTDC grids can support the AC grid operation, specifically by improving the rotor angle transient stability.

Rotor angle transient stability concerns the ability of a power system to remain in synchronism after a disturbance [2]. This implies that for a system to be stable, all the interconnected devices (generators and converters) must remain syn-

This work is supported by the French Government under the program Investissements d'Avenir (ANEITE-002-01) chronized after an incident. Transient stability enhancement through converter control can therefore follow two approaches:

- strategies aiming to enhance the synchronization capability of the converter itself following a disturbance, and

- strategies through which the converter helps other devices to remain in synchronism. The strategy proposed in this article corresponds to this approach.

Both are complementary, however if a converter loses synchronism, it will not be able to support the AC grid.

As for the first approach, the challenge lies in the fact that for converters, unlike for synchronous generators, there are no intrinsic physics governing their ability to synchronize with the grid. Their synchronization is achieved through dedicated controls. In the recent literature, the capability of Voltage Source Converters (VSC) to remain synchronized after disturbances has been studied when different controllers are implemented, for example: PLL-based controls in [3], the Power Synchronization Control in [4], the Dispatchable Virtual Oscillator in [5] and other grid-forming controllers in [6].

The second approach, on which this article is built, focuses on controllers aiming to help the surrounding system to remain in synchronism. It has been well understood that the modulation of active and reactive power of VSC-HVDC links can enhance rotor angle stability by counteracting power imbalances, e.g. in [7]-[9]. However, the operational differences between MTDC grids and HVDC links make the application of these concepts on MTDC grids not straightforward. In fact, research on the control of MTDC grids based on Line Commutated Converters (LCC) to support stability began in the past century in works like [10], [11]. All this research became more relevant when the VSC technology reached a mature level as VSCs are more adapted for multi-terminal interconnections. As a result, a new phase of research started at the beginning of the past decade with works like [12]. There, a Wide Area Control System that modulates active and reactive power references proportionally to a linear combination of all the generator speeds is proposed. In [13], a Lyapunov-based time optimal control (a bang-bang-like control) using all generators speeds to compute the sign of the power injections is proposed. There, to respect the zero power balance of the DC grid, an optimization algorithm decides which converters' references are modulated. A similar approach was implemented in [14] where a sliding mode control is proposed and a master-slave configuration is used for assuring the DC voltage stability. 
A detailed work on AC/DC transient stability is presented in [15]. There, active power strategies based on measurements of frequency at the Point of Common Coupling (PCC) of the converters are studied. The authors propose to modulate the converters' reference proportionally to the difference between their local frequency and the weighted average frequency (a linear combination of the frequencies at the PCCs). Following the same approach, in [16] it is proposed to use reactive power modulation to enhance angle stability, with the inherent advantage that reactive power limits can be managed in a decentralized manner. This strategy was improved by eliminating dedicated communication systems and instead using the DC voltage to estimate the weighted average frequency [17].

It can be noticed that most of the aforementioned strategies modulate active power references, however if the converters reach their power limits, an imbalance on the DC grid is created and the system stability can be jeopardized; even if DC voltage droop control is used. To the authors' best knowledge, none of the existing solutions coordinate the power references to keep the DC power balance while respecting the power limits of the stations in a distributed manner. Moreover, the use of the angle measurements for MTDC controllers has not been addressed in the literature. Some HVDC link projects report to use angle measurements for static purposes, e.g. in [18], however the transient behavior has not been analyzed.

This paper proposes a distributed control structure for MTDC active power modulations. The proposed control coordinates the power references to assure the zero power balance of the DC grid during transients even if converters' power limits are reached. It is then possible to take full advantage of their power headroom. The control law is a linear combination of frequencies and angles at the PCCs, which improves transient stability and follows the AC pattern of power flow, thus the stress in the post-disturbance situation is reduced.

\section{ELECTROMECHANICAL MODELING OF AC/DC POWER SYSTEMS}

The general model of an AC/DC power system is described by a set of Differential Algebraic Equations:

$$
\dot{\boldsymbol{x}}=f(\boldsymbol{x}, \boldsymbol{y}) ; \quad 0=g(\boldsymbol{x}, \boldsymbol{y}, \boldsymbol{u})
$$

where $\boldsymbol{x}, \boldsymbol{y}$ and $\boldsymbol{u}$ are vectors containing states, algebraic variables and control inputs, respectively. In the following, consider a power system composed by $n$ generators, $m$ converters and some loads, interconnected through a transmission grid with $N$ buses. The dynamic equations of the system are given by the generators' dynamics with respect to COI [19]:

$$
\begin{gathered}
\dot{\tilde{\delta}}_{i}=\tilde{\omega}_{i}, \quad M_{i} \dot{\tilde{\omega}}_{i}=-K_{D, i} \tilde{\omega}_{i}+P_{m, i}-P_{e, i}-\frac{M_{i}}{M_{T}} P_{C O I}, \text { (2) } \\
P_{e, i}=\frac{E_{q, i}^{\prime} V_{g, i}}{X_{d, i}^{\prime}} \sin \left(\delta_{i}-\theta_{g, i}\right), \quad Q_{e, i}=\frac{V_{g, i}^{2}}{X_{d, i}^{\prime}}-\frac{E_{q, i}^{\prime} V_{g, i}}{X_{d, i}^{\prime}} \cos \left(\delta_{i}-\theta_{g, i}\right),
\end{gathered}
$$

where $P_{C O I}=\sum_{i=1}^{n}\left(P_{m, i}-P_{e, i}\right)$. For each $i$ generator, $\tilde{\delta}_{i}$ is the rotor angle deviation with respect to the COI, $\tilde{\omega}_{i}$ is the rotor speed deviation with respect to the COI, $M_{i}$ is the inertia coefficient, $P_{m, i}$ is the mechanical power, $P_{e, i}$ is the electrical output power, $Q_{e, i}$ is the generated reactive power and $X_{d, i}^{\prime}$ is the transient reactance. The complex internal voltage of the generator is $\bar{E}_{d, i}^{\prime}=E_{d, i}^{\prime} \angle \delta_{i}$, while the voltage at the generator terminals is $\bar{V}_{g, i}=V_{g, i} \angle \theta_{g, i}$. The state vector of the system is $\boldsymbol{x}=\left[\begin{array}{ll}\boldsymbol{\delta} & \boldsymbol{\omega}\end{array}\right]^{T}=\left[\begin{array}{llllll}\tilde{\delta}_{1} & \cdots & \tilde{\delta}_{n} & \tilde{\omega}_{1} & \cdots & \tilde{\omega}_{n}\end{array}\right]^{T}$.

The algebraic variables of the system are the complex voltages of every bus in the grid in the COI frame $\boldsymbol{y}=\left[\begin{array}{ll}\boldsymbol{V} & \tilde{\boldsymbol{\theta}}\end{array}\right]^{T}$, with:

$$
\begin{aligned}
\mathbf{V} & =\left[\begin{array}{lllll}
\mathbf{V}_{g} & \mathbf{V}_{h v d c} & V_{n+m+1} & \ldots & V_{N}
\end{array}\right]^{T}=\left[\begin{array}{llll}
V_{1} & \ldots & V_{N}
\end{array}\right]^{T}, \\
\tilde{\boldsymbol{\theta}} & =\left[\begin{array}{lllll}
\tilde{\boldsymbol{\theta}}_{g} & \tilde{\boldsymbol{\theta}}_{h v d c} & \tilde{\theta}_{n+m+1} & \ldots & \tilde{\theta}_{N}
\end{array}\right]^{T}=\left[\begin{array}{llll}
\tilde{\theta}_{1} & \ldots & \tilde{\theta}_{N}
\end{array}\right]^{T},
\end{aligned}
$$

where $\bar{V}_{h v d c, k}=V_{h v d c, k} \angle \tilde{\theta}_{h v d c, k} \quad(\forall k=1 \ldots m)$ is the voltage at the PCC for each converter and $\bar{V}_{i}=V_{i} \angle \tilde{\theta}_{i}(\forall i=$ $n+m+1 \ldots N)$ are the voltages at buses without generators nor converters. The algebraic equations are the power mismatch equations at every bus. For a lossless transmission system the following equations are written at bus $i$, where $P_{i}$ is the active power and $Q_{i}$ is the reactive power injected to the bus $i$. For $i=1 \ldots n$ (buses with generators):

$$
\begin{aligned}
P_{i} & =-P_{e, i}+\sum_{j=1}^{N} V_{i} V_{j} B_{i j} \sin \theta_{i j}, \\
Q_{i} & =-Q_{e, i}-\sum_{j=1}^{N} V_{i} V_{j} B_{i j} \cos \theta_{i j}
\end{aligned}
$$

where $\theta_{i j}=\tilde{\theta}_{i}-\tilde{\theta}_{j}=\theta_{i}-\theta_{j}$ and $B_{i j}$ is the equivalent susceptance between bus $i$ and $j$. Then, for $i=n+1 \ldots n+m$ (buses with HVDC converters):

$$
\begin{aligned}
P_{i} & =P_{h v d c, k}+\sum_{j=1}^{N} V_{h v d c, k} V_{j} B_{i j} \sin \left(\theta_{h v d c, k}-\theta_{j}\right), \\
Q_{i} & =Q_{h v d c, k}-\sum_{j=1}^{N} V_{h v d c, k} V_{j} B_{i j} \cos \left(\theta_{h v d c, k}-\theta_{j}\right)
\end{aligned}
$$

where $P_{h v d c, k}$ and $Q_{h v d c, k}$ are the active and reactive power injections of the converters. The power flow direction is chosen to be positive when power is flowing into the DC grid. For the remaining buses $i=(n+m+1) \ldots N$ :

$$
P_{i}=\sum_{j=1}^{N} V_{i} V_{j} B_{i j} \sin \theta_{i j}, Q_{i}=-\sum_{j=1}^{N} V_{i} V_{j} B_{i j} \cos \theta_{i j}
$$

From Kirchhoff's laws, at each bus we have:

$$
P_{i}+P_{\text {load }, i}=0 ; Q_{i}+Q_{\text {load }, i}=0
$$

where $P_{l o a d, i}$ and $Q_{\text {load }, i}$ are the active and reactive power of the load connected at bus $i$.

Regarding the MTDC grid, the modeling of the VSC stations depends on the implemented converter controls, more particularly the outer loops. In this article, the proposed supplementary control layer aims to modulate in a coordinated manner the active power set-points of the VSCs whose internal control is adapted for tracking power references. Hence, as done in [13], [20], the VSCs are represented as controllable active power injections comprising two terms as follows:

$$
P_{h v d c, k}=P_{h v d c 0, k}+\Delta P_{h v d c, k}
$$


where $P_{h v d c 0, k}$ are the set-points determined by the system operator, $\Delta P_{h v d c, k}$ are the part of the reference to be modulated, thus the control input of the $\mathrm{AC} / \mathrm{DC}$ grid. Consequently, the input vector of the complete AC/DC system is defined as:

$$
\boldsymbol{u}=\boldsymbol{\Delta} \boldsymbol{P}_{\boldsymbol{h v d c}}=\left[\Delta P_{h v d c, 1} \cdots \Delta P_{h v d c, m}\right]^{T}
$$

In the literature, many converter controllers that enable multi-terminal configurations have been proposed. The ability of a converter to fast track the power references, depends on the implemented internal control as well as on the system conditions. Considering that for the analysis VSCs are represented as controllable power injections, the proposals and conclusions of this article are more pertinent when using converters with fast power tracking capability (see e.g. [21]-[23]).

The presented simplified models of generators, lines, loads and converters are used for the analysis and the proposition of controls, however in Section V detailed EMT models of the AC/DC grid components are used to perform simulations.

\section{NEED OF SUPPLEMENTARY CONTROLLERS}

This section studies the transient stability margins when a system is reinforced with an MTDC grid, instead of an HVAC grid. To this end, the multi-machine system with an embedded 3 -terminal HVDC grid in Figure $1 \mathrm{~b}$ is used. In this system a group of $\mathrm{AC}$ lines in system in Figure 1a has been replaced by the MTDC grid (half of the AC lines are replaced).

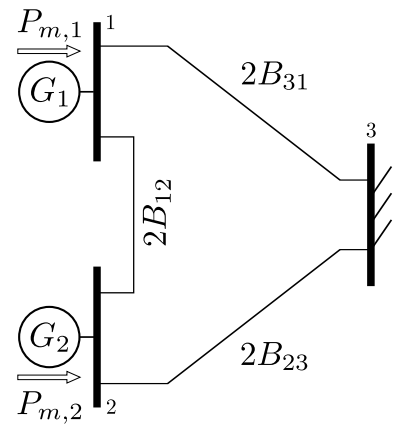

(a) $\mathrm{AC}$

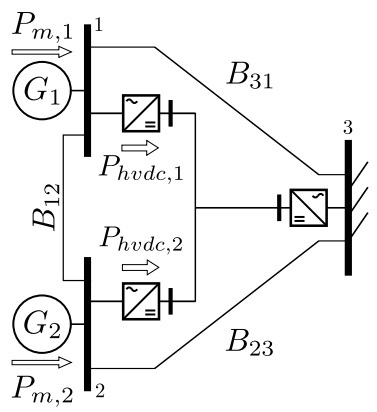

(b) $\mathrm{AC} / \mathrm{DC}$
Fig. 1: Systems under comparison

The dynamics of the systems are described by the following equations (the third node is considered as an infinite bus): a) $\mathrm{AC}$ system

$$
\begin{gathered}
\dot{\tilde{\delta}}_{1}=\tilde{\omega}_{1}, \quad \dot{\tilde{\delta}}_{2}=\tilde{\omega}_{2} \\
\dot{\tilde{\omega}}_{1}=\frac{1}{M_{1}}\left(P_{m, 1}-2 P_{\max , 12} \sin \delta_{12}-2 P_{\max , 31} \sin \tilde{\delta}_{1}\right) \\
\dot{\tilde{\omega}}_{2}=\frac{1}{M_{2}}\left(P_{m, 2}+2 P_{\max , 12} \sin \delta_{12}-2 P_{\max , 23} \sin \tilde{\delta}_{2}\right)
\end{gathered}
$$

b) $\mathrm{AC} / \mathrm{DC}$ system

$$
\begin{aligned}
& \dot{\tilde{\delta}}_{1}=\tilde{\omega}_{1} \quad, \quad \dot{\tilde{\delta}}_{2}=\tilde{\omega}_{2} \\
& \dot{\tilde{\omega}}_{1}=\frac{1}{M_{1}}\left(P_{m, 1}-P_{\max , 12} \sin \delta_{12}-P_{\max , 31} \sin \tilde{\delta}_{1}-P_{h v d c, 1}\right) \\
& \dot{\tilde{\omega}}_{2}=\frac{1}{M_{2}}\left(P_{m, 2}+P_{\max , 12} \sin \delta_{12}-P_{\max , 23} \sin \tilde{\delta}_{2}-P_{h v d c, 2}\right)
\end{aligned}
$$

with $\delta_{i j}=\tilde{\delta}_{i}-\tilde{\delta}_{j}$ and $P_{\max , i j}=E_{d, i}^{\prime} E_{d, j}^{\prime} B_{i j}$.

Equations (10) and (11) are derived following the assumption that internal reactances of generators are negligible against the transmission lines (i.e. $E_{d, i}^{\prime} \angle \delta_{i} \approx V_{h v d c, i} \angle \theta_{h v d c, i}$ ), and converters are connected very close to the generators (i.e. the $i-t h$ converter power injection only has an influence on the dynamics of the $i-t h$ machine). This assumptions can also be understood as each generator representing an aggregation of an electrical area with many generators. As more generators are connected in parallel, their Thevenin's equivalent reactance would tend to be smaller. Besides, by assuming $E_{d, i}^{\prime} \angle \delta_{i} \approx V_{h v d c, i} \angle \theta_{h v d c, i}$ the algebraic variables of the system (complex voltages at the buses) can be eliminated, so the system can be described by a set of Ordinary Differential Equations $(\dot{x}=\boldsymbol{f}(\boldsymbol{x}, \boldsymbol{u}))$, which ease the following numerical application

The characteristics of the systems are summarized in Table I. The stable equilibrium point (SEP) of is noted $x^{s}=$ $\left(\tilde{\delta}_{1}^{s}, \tilde{\delta}_{2}^{s}, \tilde{\omega}_{1}^{s}=0, \tilde{\omega}_{2}^{s}=0\right)$.

TABLE I: Parameters of the system and load-flow results

\begin{tabular}{ccccc}
\hline $\begin{array}{c}\text { Zone } \\
\text { (i) }\end{array}$ & $\begin{array}{c}M_{i} \\
{[\mathrm{~s}]}\end{array}$ & $\begin{array}{c}P_{m, i} \\
\text { [p.u.] }\end{array}$ & $\begin{array}{c}P_{h v d c_{i}} \\
{[\mathrm{p} . \mathrm{u} .]}\end{array}$ & $\begin{array}{c}\tilde{\delta}_{i} \\
{[\mathrm{deg}]}\end{array}$ \\
\hline 1 & 5 & 1 & 0.5 & 15 \\
2 & 4 & 0.6 & 0.3 & 7 \\
3 & $\infty$ & -1.6 & -0.8 & 0 \\
\hline
\end{tabular}

\begin{tabular}{cc}
\hline $\begin{array}{c}\text { Zones } \\
\text { (i-j) }\end{array}$ & $\begin{array}{c}P_{\max , i j} \sin \delta_{i j}^{s} \\
\text { [p.u.] }\end{array}$ \\
\hline $1-2$ & 0.1 \\
$2-3$ & 0.4 \\
$3-1$ & -0.4 \\
\hline
\end{tabular}

The assumption of equivalence between both systems lies on the fact that they have the same SEP. For that purpose, power references for the converters are calculated for obtaining the same power flowing through the MTDC than in the original AC lines (e.g. $P_{h v d c_{1}}=P_{\max , 12} \sin \delta_{12}^{s}+P_{\max , 31} \sin \delta_{1}^{s}$ ). Via numerical integration, the SEP and the Unstable Equilibrium Points (UEPs), noted $x_{i}^{u}=\left(\tilde{\delta}_{1, i}^{u}, \tilde{\delta}_{2, i}^{u}\right)$, are computed for both systems and summarized in Table II. For both systems, all UEPs are found to be the exactly same (this can be further confirmed in Figure 2). The coordinates of the UEPs can be used to estimate the Region of Attraction. As both systems under study have the same UEPs, their estimated region of attraction in the angle space is the same. More information is needed in order to compare their transient stability margins.

To get an overview of the system behavior, the following Transient Energy Function (TEF) is analyzed for both systems:

$$
\mathcal{V}(\boldsymbol{\omega}, \boldsymbol{\delta})=\mathcal{V}_{K E}(\boldsymbol{\omega})+\mathcal{V}_{P E}(\boldsymbol{\delta})+C_{0}, \quad C_{0}=-\mathcal{V}_{P E}\left(x^{s}\right)
$$

where $\mathcal{V}_{K E}$ and $\mathcal{V}_{P E}$ are the kinetic and potential energies respectively. The potential energy of systems in Equations 10 and 11 is computed as follows:

a) For the $\mathrm{AC}$ system:

$$
\begin{aligned}
\mathcal{V}_{P E}^{a c}= & -P_{m, 1} \tilde{\delta}_{1}-P_{m, 2} \tilde{\delta}_{2}-2 P_{\max , 12} \cos \left(\tilde{\delta}_{1}-\tilde{\delta}_{2}\right) \\
& -2 P_{\max , 23} \cos \tilde{\delta}_{2}-2 P_{\max , 31} \cos \tilde{\delta}_{1}+C_{0}^{a c}
\end{aligned}
$$

b) For the AC/DC System:

$$
\begin{aligned}
\mathcal{V}_{P E}^{d c}= & -P_{m, 1} \tilde{\delta}_{1}-P_{m, 2} \tilde{\delta}_{2}-P_{\max , 12} \cos \left(\tilde{\delta}_{1}-\tilde{\delta}_{2}\right) \\
& -P_{\max , 23} \cos \tilde{\delta}_{2}-P_{\max , 31} \cos \tilde{\delta}_{1} \\
& +P_{h v d c, 1} \tilde{\delta}_{1}+P_{h v d c, 2} \tilde{\delta}_{2}+C_{0}^{d c}
\end{aligned}
$$




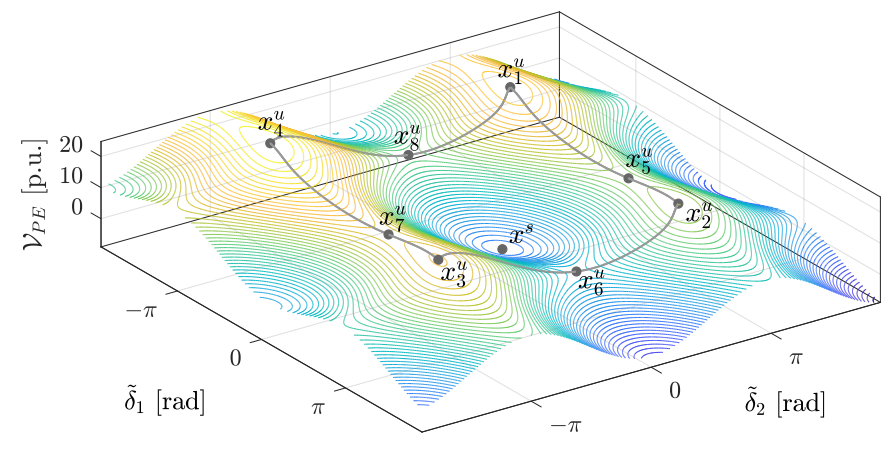

(a) AC system

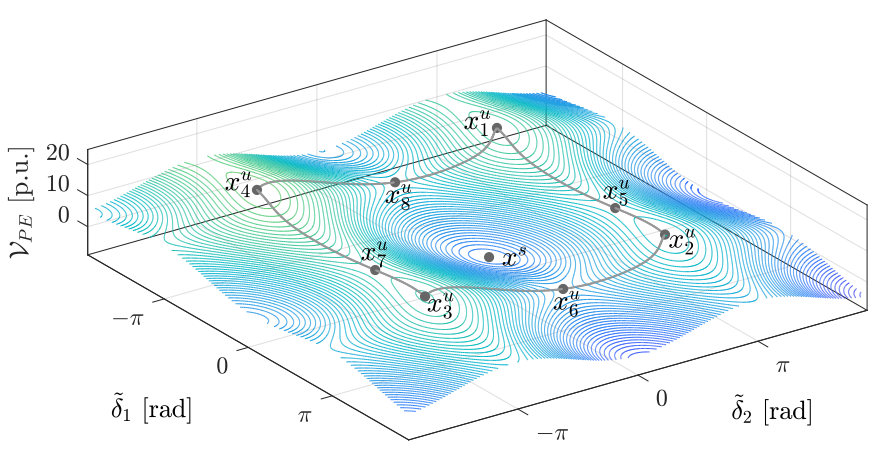

(b) AC/DC system

Fig. 2: Equi-potential contours and stability region delimited by the Potential Energy Boundary Surface

In the transient stability assessment, it is common practice to quantify transient stability limits in terms of the critical energy [24], which is the minimum necessary energy the system has to receive (in this case by a disturbance) to become unstable. The Closest Unstable Equilibrium Point method [25] states that a first approximation of the critical energy, corresponds to the energy at the UEP with lowest potential energy. For a general comparison the energy of both systems at all the UEPs is computed. The results are presented in Table II

TABLE II: Comparison of the potential energy at the UEPs

\begin{tabular}{ccccc}
\hline \multirow{2}{*}{ UEP } & \multicolumn{2}{c}{ Angles } & \multicolumn{2}{c}{ Potential Energy [p.u.] } \\
& $\tilde{\delta}_{1}^{u}[\mathrm{rad}]$ & $\tilde{\delta}_{2}^{u}[\mathrm{rad}]$ & AC system & AC/DC system \\
\hline$x_{1}^{u}$ & -3.84 & 3.2 & 21.5 & 10.25 \\
$x_{2}^{u}$ & 2.44 & 3.2 & 14.76 & 7.38 \\
$x_{3}^{u}$ & 2.44 & -3.08 & 18.54 & 9.27 \\
$x_{4}^{u}$ & -3.84 & -3.08 & 24.82 & 12.41 \\
$x_{5}^{u}$ & 0.62 & 3.17 & 13.96 & 6.98 \\
$x_{6}^{u}$ & 2.97 & 0.16 & 6.12 & 3.06 \\
$x_{7}^{u}$ & 0.62 & -3.11 & 17.74 & 8.87 \\
$x_{8}^{u}$ & -3.31 & 0.16 & 12.4 & 6.2 \\
\hline
\end{tabular}

As It is observed, the energy in every UEP is lower in the AC/DC system than in the AC system. Therefore, for the given equilibrium point $x^{s}$, stability margins are twice higher in the AC system than in the AC/DC system. Graphically, this comparison can be done based on the potential energy surfaces on the angle space, plotted in Figure 2. It is easy to observe that the closest UEP corresponds to $x_{6}^{u}$, since it is the exit point of the stability region with lower potential energy.

In conclusion, compared with an equivalent $\mathrm{AC}$ transmission system, a hybrid AC/DC transmission system can have lower transient stability margins, for the same operating point. This difference is due to the synchronizing nature of the $\mathrm{AC}$ lines; the transmitted power as function of the transport angle contribute to increase the transient stability margins. Thus, while AC lines intrinsically increase the transient stability margins, HVDC grids with constant power references do not. In the presented example, the MTDC grid of the AC/DC system replaced half of the $\mathrm{AC}$ transmission lines in the $\mathrm{AC}$ system, resulting in decreased stability margins. If the MTDC grid replaced a larger part of the AC lines, the stability margins would be even lower. It is interesting to remark that, if $100 \%$ of the $\mathrm{AC}$ lines were replaced by $\mathrm{DC}$ lines, the problem of transient stability would be non-existent. In such a case, the three asynchronous areas would be connected through the MTDC grid, which would aggravate the frequency stability of each zone. It is therefore clear that additional control layers are needed to involve the MTDC grid in the stabilization of the system. Different approaches can be adopted: open-loop optimization of HVDC set-points [26], threshold emergency actions [27], etc. In this paper a dynamic feedback controller for modulating the MTDC grid references is proposed in the following section.

\section{THE PROPOSED CONTROL STRUCTURE}

The proposed control structure is composed of two parts: (i) The control law, which consists in a distributed feedback control algorithm based on the measurements of angles and frequency at all the PCCs of the converters. Through communication between local controllers the control actions of a pair of converters can be matched, if a converter $i$ modulates its power, converter $j$ modulates the same amount of power in the opposite direction. The pair $i j$ is called Virtual link in the following. As explained later the control law makes each Virtual Link to inject damping and synchronizing power.

(ii) Decentralized limitation of active power modulations. The modulations of power references of virtual links are limited by local controllers to a maximum and a minimum value. These values are designed in order to respect the power limits of the converters.

\section{A. The control law}

The proposed control law is motivated by the results in [8] and [15] where the frequencies at the PCCs of converters are used as feedback signals for point-to-point and MTDC systems respectively. Moreover, the use of angle measurements implemented in an embedded HVDC link in [18], [28] is extrapolated for its use in MTDC grids. The proposed control law is:

$$
\Delta P_{h v d c}=-\left[\begin{array}{ll}
K_{\omega} & K_{\delta}
\end{array}\right]\left[\begin{array}{c}
\dot{\theta}_{h v d c} \\
\theta_{h v d c}-\bar{\theta}
\end{array}\right]
$$




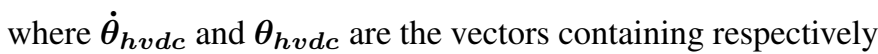
the frequencies and the voltage phase angles at the converters' PCCs, $\overline{\boldsymbol{\theta}}$ is a vector of the angle references, $\boldsymbol{K}_{\omega}$ and $\boldsymbol{K}_{\delta}$ $(m \times m)$ are the control gains. In addition to enhance transient stability, converters provide other active power services to the grid, such as frequency support or DC voltage control. The proposed control law aims not to interact with such controllers, hence the sum of power references of considered converters must be zero at every instant (i.e. $\sum_{l=1}^{m} \Delta P_{h v d c, k}=0$ ). One manner to reach this objective in a distributed manner is by the correct selection of the control gains. To this end, the following constraints to the control gains are set:

$$
\begin{aligned}
& k_{\omega, k j}=k_{\omega, j k} ; \quad k_{\omega, j j}=-\sum_{k=1, k \neq j}^{m} k_{\omega, k j} \\
& k_{\delta, k j}=k_{\delta, j k} ; \quad k_{\delta, j j}=-\sum_{k=1, k \neq j}^{m} k_{\delta, k j}
\end{aligned}
$$

Consequently, matrices $\boldsymbol{K}_{\boldsymbol{\omega}}$ and $\boldsymbol{K}_{\boldsymbol{\delta}}$, have the same structure as a Nodal Admittance Matrix (or Laplacian matrix) with no shunt elements. Applying constrains in Equation (16) into the control law in Equation (15), the supplementary active power reference of the $k-t h$ converter is:

$$
\Delta P_{h v d c, k}=\Delta P_{\text {damp }, k}+\Delta P_{\text {synch }, k}
$$

with

$$
\begin{aligned}
\Delta P_{d a m p, k} & =\sum_{j=1}^{m} k_{\omega, k j}\left(\dot{\theta}_{h v d c, k j}\right)=\sum_{j=1}^{m} \Delta P_{d a m p, k j} \\
\Delta P_{\text {synch }, k} & =\sum_{j=1}^{m} k_{\delta, k j}\left(\theta_{h v d c, k j}-\bar{\theta}_{k j}\right)=\sum_{j=1}^{m} \Delta P_{\text {synch }, k j}
\end{aligned}
$$

with $\dot{\theta}_{h v d c, k j}=\dot{\theta}_{h v d c, k}-\dot{\theta}_{h v d c, j}, \theta_{h v d c, k j}=\theta_{h v d c, k}-\theta_{h v d c, j}$, $\bar{\theta}_{k j}=\bar{\theta}_{k}-\bar{\theta}_{j}$. Hence, since $\theta_{h v d c, k j}=-\theta_{h v d c, j k}$, the control action of the converter $k$ for the pair $k-j$ is opposite to the one of the converter $j$ at every instant. For example:

$$
\begin{gathered}
\overbrace{k_{\omega, k j} \dot{\theta}_{h v d c, k j}}^{\Delta P_{\text {damp }, k j}}=-\overbrace{k_{\omega, j k} \dot{\theta}_{h v d c, j k}}^{\Delta P_{\text {damp }, j k}} \\
\overbrace{k_{\delta, k j}\left(\theta_{h v d c, k j}-\bar{\theta}_{k j}\right)}^{\Delta P_{s y n c h, k j}}=-\overbrace{k_{\delta, j k}\left(\theta_{h v d c, j k}-\bar{\theta}_{j k}\right)}^{\Delta P_{s y n c h, j k}}
\end{gathered}
$$

Therefore, the power injected into the grid by converter $k$ is evacuated by converter $j$. From the AC grid perspective, each pair of converters can be interpreted as an unified actuator or a Virtual link $k j$ transferring power from the AC bus $k$ to the AC bus $j$, independently of the DC grid topology. The power flowing through the virtual link $k j$ can be defined as follows:

$$
P_{\text {link }, k j}=\Delta P_{\text {damp }, k j}+\Delta P_{\text {synch }, k j}
$$

To keep coherency with the existing literature, in the following, the control part acting on the frequency differences is referred as the Frequency Difference Controller (FDC), and the part of the controller injecting power proportional to angles is called the Angle Difference Controller (ADC) [18].

To better explain the Virtual Link concept, consider the embedded 3-terminal HVDC grid in Figure 3. Suppose that

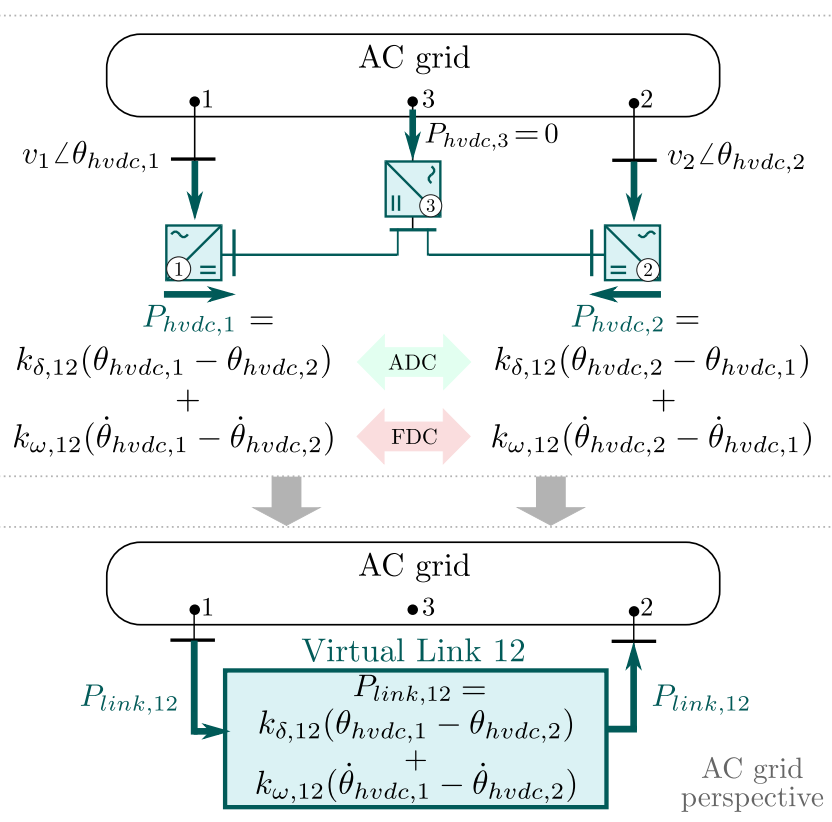

Fig. 3: Example of a virtual link between stations 1 and 2

the active power set-points of the 3 converters given by the operator are set to zero (i.e. $P_{h v d c 0, k}=0, k=1,2,3$ ) so we can focus only on the active power modulations. For the sake of understanding, we will consider only the Virtual link between stations 1 and 2 (i.e. $k_{\delta, 23}=k_{\delta, 31}=k_{\omega, 23}=k_{\omega, 31}=0$ and $k_{\delta, 12}>0, k_{\omega, 12}>0$ ); we consider also that all angle references are zero (i.e. $\bar{\theta}=\mathbf{0}$ ). As shown in the first part of Figure 3, the modulated power of each station is given by Equation (17). It is observed that the modulated power of Station $1\left(P_{h v d c, 1}\right)$ is exactly the same as Station $2\left(P_{h v d c, 2}\right)$, but in the opposite direction (as in Equation (20)). If Station 2 extracts the same amount of power injected by Station 1, the power balance in the DC grid is preserved. Furthermore, from the AC grid perspective (second part of Figure 3), some power is extracted from Bus 1 and injected in Bus 2 as function of their angle difference (similar to an AC line) and their frequency difference (similar to the damping controller in [29] for an HVDC link). By an abuse of language, we can say that the ADC behaves as a network of admittances connecting all PCCs and the FDC as a network of "electrical dampers" (in a mechanical analogue: a network of springs and dampers).

\section{B. Analysis of the control law}

Consider the bus where the $k-t h$ converter is connected. When the control law in (18) and (19) is applied, the active power mismatch equation including loads in (5), becomes:

$$
\begin{gathered}
P_{h v d c 0, k}+\sum_{j=1}^{m} k_{\omega, k j} \dot{\theta}_{h v d c, k j} \\
+\sum_{j=1}^{m} k_{\delta, k j} \theta_{h v d c, k j}-\sum_{j=1}^{m} k_{\delta, k j} \bar{\theta}_{k j} \\
+\sum_{j=1}^{N} V_{h v d c, k} V_{j} B_{i j} \sin \left(\theta_{h v d c, k}-\theta_{j}\right)+P_{\text {load }}=0
\end{gathered}
$$


The impact of the controller on the energy of the closed loop system can be analyzed through the following candidate function - representing the kinetic and potential energieswhich is proposed based on the results in [19]:

$$
\mathcal{V}(\tilde{\boldsymbol{\delta}}, \tilde{\boldsymbol{\omega}}, \mathbf{V}, \boldsymbol{\theta})=\mathcal{V}_{K E}+\sum_{i=1}^{6} \mathcal{V}_{P E, i}+C_{0}
$$

with:

$$
\begin{gathered}
\mathcal{V}_{K E}(\tilde{\boldsymbol{\omega}})=\frac{1}{2} \sum_{i=1}^{n} M_{i} \tilde{\omega}_{i}^{2}, \quad \mathcal{V}_{P E, 1}(\tilde{\boldsymbol{\delta}})=-\sum_{i=1}^{n} P_{m, i} \tilde{\delta}_{i} \\
\mathcal{V}_{P E, 2}(\boldsymbol{\theta}, \mathbf{V})=-\frac{1}{2} \sum_{i=1}^{N} \sum_{j=n+1}^{N} V_{i} V_{j} B_{i j} \cos \theta_{i j} \\
\mathcal{V}_{P E, 3}(\boldsymbol{\theta})=\sum_{k=1}^{m} P_{h v d c 0, k} \tilde{\theta}_{h v d c, k}, \mathcal{V}_{P E, 4}(\boldsymbol{\theta})=\frac{1}{4} \sum_{k=1}^{m} \sum_{j=1}^{m} k_{\delta, k j} \theta_{h v d c, k j}^{2}, \\
\mathcal{V}_{P E, 5}(\boldsymbol{\theta})=-\frac{1}{2} \sum_{k=1}^{m} \sum_{j=1}^{m} k_{\delta, k j} \bar{\theta}_{k j} \theta_{h v d c, k j}, \\
\mathcal{V}_{P E, 6}(\mathbf{V})=-\sum_{k=1}^{m} Q_{h v d c, k} \ln \left(\frac{V_{h v d c, k}}{V_{h v d c, k}^{s}}\right)
\end{gathered}
$$

where $C_{0}$ is the potential energy $\sum_{i=1}^{6} \mathcal{V}_{P E, i}$ evaluated at the equilibrium point. For simplicity, the transient energy functions corresponding to loads are not included, however if constant power loads are considered, they can be treated as HVDC constant power injections (their energy functions will be similar to $\mathcal{V}_{P E, 3}$ and $\mathcal{V}_{P E, 6}$ ). If other types of loads are considered (voltage or frequency dependent), their transient energy functions can be found in [19].

In [8], [19] it has been shown that the energy function of a power system without supplementary controllers $\left(\mathcal{V}_{\text {unctr }}\right)$ as well as its time derivative $\left(\dot{\mathcal{V}}_{\text {unctr }}\right)$ are respectively:

$$
\begin{gathered}
\mathcal{V}_{\text {unctr }}=\mathcal{V}_{K E}+\mathcal{V}_{P E, 1}+\mathcal{V}_{P E, 2}+\mathcal{V}_{P E, 3}+\mathcal{V}_{P E, 6}+C_{0} \\
\dot{\mathcal{V}}_{\text {unctr }}=-\sum_{i=1}^{n} k_{D, i}\left(\tilde{\omega}_{i}\right)^{2}
\end{gathered}
$$

With respect to the uncontrolled system energy function $\mathcal{V}_{\text {unctr }}$, in the proposed function $\mathcal{V}$ in Equation (23) terms $\mathcal{V}_{P E, 4}$ and $\mathcal{V}_{P E, 5}$ have been added. These terms are added by the proposed controller and depend exclusively on the angle vector. Therefore, to test the negativeness of the derivative of $\mathcal{V}$, only the time derivative of $\mathcal{V}$ along the angles trajectory must be calculated. The time derivative of $\mathcal{V}$ with respect to the angle at the PCC of converter $k$ is given by:

$$
\begin{gathered}
\frac{\partial \mathcal{V}}{\partial \tilde{\theta}_{h v d c, k}} \dot{\tilde{\theta}}_{h v d c, k}=\left[P_{h v d c 0, k}+\sum_{j=1}^{m} k_{\delta, k j} \theta_{h v d c, k j}-\sum_{j=1}^{m} k_{\delta, k j} \bar{\theta}_{k j}\right. \\
\left.+\sum_{j=1}^{N} V_{h v d c, k} V_{j} B_{i j} \sin \left(\theta_{h v d c, k}-\theta_{j}\right)+P_{l o a d, i}\right] \dot{\tilde{\theta}}_{h v d c, k}
\end{gathered}
$$

The substitution of Equation (22) in Equation (26), yields:

$$
\frac{\partial \mathcal{V}}{\partial \tilde{\theta}_{h v d c, k}} \dot{\tilde{\theta}}_{h v d c, k}=-\sum_{j=1}^{m} k_{\omega, k j} \dot{\theta}_{h v d c, k j} \dot{\tilde{\theta}}_{h v d c, k}
$$

The sum over the $m$ buses with HVDC infeed gives the derivative of $\mathcal{V}$ along the vector of angles at the PCCs:

$$
\begin{aligned}
\frac{\partial \mathcal{V}}{\partial \tilde{\boldsymbol{\theta}}_{h v d c}} \dot{\tilde{\boldsymbol{\theta}}}_{h v d c} & =-\sum_{k=1}^{m} \sum_{j=1}^{m} k_{\omega, k j} \dot{\theta}_{h v d c, k j} \dot{\tilde{\theta}}_{h v d c, k} \\
& =-\frac{1}{2} \sum_{j=1}^{m} \sum_{k=1}^{m} k_{\omega, k j}\left(\dot{\theta}_{h v d c, k j}\right)^{2}
\end{aligned}
$$

From Equations (25) and (28) one can conclude that the time derivative of the energy function for the closed loop system including the ADC and the FDC is given by:

$$
\dot{\mathcal{V}}=-\sum_{i=1}^{n} k_{D, i}\left(\tilde{\omega}_{i}\right)^{2}-\frac{1}{2} \sum_{j=1}^{m} \sum_{k=1}^{m} k_{\omega, k j}\left(\dot{\theta}_{h v d c, k j}\right)^{2} \leq 0
$$

Theorem IV.1. The overall closed loop system is stable. Furthermore, all frequencies will converge to the COI, represented by the equilibrium point given by $\left\{\tilde{\omega}_{i} \dot{\theta}_{h v d c, k}\right\}=0$.

Proof. The first part is a direct consequence of Lyapunov theorem. Equation (23) is indeed a Lyapunov function and the fact that its derivative (29) is negative semidefinite assures stability of all states. For the second part, we call upon La Salle's theorem that assures that the states will converge to the largest invariant set that assures that (29) is equal to zero, what is only valid when $\left\{\tilde{\omega}_{i} \dot{\theta}_{h v d c, k j}\right\}=0$.

\section{Remarks:}

- The FDC impacts the rate of change of energy (see Equation (29)) while the ADC impacts the potential energy (see Equation (23)). The ADC does not help to dissipate the transient energy, but since $\mathcal{V}_{P E, 4}$ is positive semidefinite, the ADC increases the potential energy of the UEPs, hence the exit points. In order to maximize the ADC contribution to the potential energy, any constant component of the active power references should be set to zero, i.e. $\overline{\boldsymbol{\theta}}=0$ and $\boldsymbol{P}_{\boldsymbol{h} \boldsymbol{v d c 0}}=0$. This makes zero the functions $\mathcal{V}_{P E, 3}$ and $\mathcal{V}_{P E, 5}$, which are not positive semidefinite functions.

- Power injections due to the ADC controller are different from zero in the post-event SEP if there is a modification in the power flow (line tripping, change in generator's reference, random load variations, etc.), this motivates its use for static purposes. Indeed, in practical applications, it is suggested not to have any constant component of the active power references (i.e. to set $\overline{\boldsymbol{\theta}}=0$ and $\boldsymbol{P}_{\boldsymbol{h v d c 0}}=0$ ), and let the ADC make the MTDC follow the natural pattern of the AC power-flow, as a network of AC lines would naturally do. This choice allows to avoid active power loop-flows in the surrounding AC lines [18] and simplifies the task for the TSO since it is not necessary to periodically re-dispatch angle and active power references.

- In this analysis, structural limits of the converters and their controllers are not taken into account. Clearly, improving transient stability through power modulations requires available power headroom in the converters. The larger the available headroom, the more aggressive the actions of the actuators (i.e. the converters) can be. 
- More detailed models of synchronous machines and loads can be consider for the stability analysis, their energy functions can be found in [19]. The classical model of generators is considered in this paper for the sake of simplicity, however stability conclusions of the controller remain valid for other generator and load models.

\section{Decentralized coordination of active power limits}

Although the proposed control law requires communication between converters, our aim is to propose an architecture where control input limits are computed locally at the converter level. In order to assure the zero-power balance of the DC grid in the case any of the converters reach its active power limits, the control actions of the virtual links must be limited in a coordinated manner. The set of constraints that must be fulfilled is defined by the fact that the sum of powers of the virtual links "connected" to a converter shouldn't exceed the rated power of the converter, therefore one can write:

$$
\begin{aligned}
P_{h v d c, k}^{\max }-P_{h v d c 0, k}= & \overbrace{\Delta P_{h v d c, k}^{\text {max }}}^{\text {Pos. power reserve }} \geq \sum_{j=1}^{m} P_{l i n k, k j}^{\max }, \\
P_{h v d c, k}^{\min }-P_{h v d c 0, k}= & \overbrace{\Delta P_{h v d c, k}^{\text {min }}}^{\text {Neg. power reserve }} \leq \sum_{j=1}^{m} P_{l i n k, k j}^{\text {min }},
\end{aligned}
$$

for $k, j=1 \ldots, m$, whith

$$
P_{l i n k, k j}^{\max }=-P_{l i n k, j k}^{\min }
$$

where $P_{l i n k, k j}^{\max }$ and $P_{l i n k, k j}^{\min }$ are the upper and lower limits of the power flowing through the virtual link $k j . P_{h v d c, k}^{\max }$ and $P_{h v d c, k}^{\min }$ are the upper and lower limits of converter $k$. The later limits can be defined by the rated power of the converter. If other controls require power reserves (e.g. $v_{d c}$ droop or freq. droop), limits $P_{h v d c, k}^{\max }$ and $P_{h v d c, k}^{\min }$ can be tightened. Equations in (30), provide a set of $2 w$ linear dependent equations ( $w$ is the number of virtual links), in order to find the $2 w$ limits of virtual links. An example of the implementation of the control is given in the following section.

\section{APPLiCATION ON A TEST SYSTEM}

\section{A. Description of the power system}

The proposed control has been implemented and tested on a modified version of the New England IEEE 39-Bus System build on the EMTP-RV software. An MTDC grid has been installed in the test system connecting buses 2, 6, 22 and 29. An overview of the system is shown in Figure 4. With respect to the original system, the following modifications were made in order to generate a heavily loaded case:

- $G_{1}$ does not represent an infinite bus anymore, it has been replaced by a generator of rated power of 1000 MVA.

- Loads of 500MW and 600MW were connected to buses 2 and 6 respectively. Load 26 increments 400MW.

- Generation of $G_{6}$ and $G_{9}$ has been augmented to $1.4 \mathrm{GW}$ and $1 \mathrm{GW}$ respectively. Their rated power is 2000MVA.

The embedded MTDC grid is a 4-terminal DC grid in mono polar configuration with a rated DC voltage of $320 \mathrm{kV}$. The

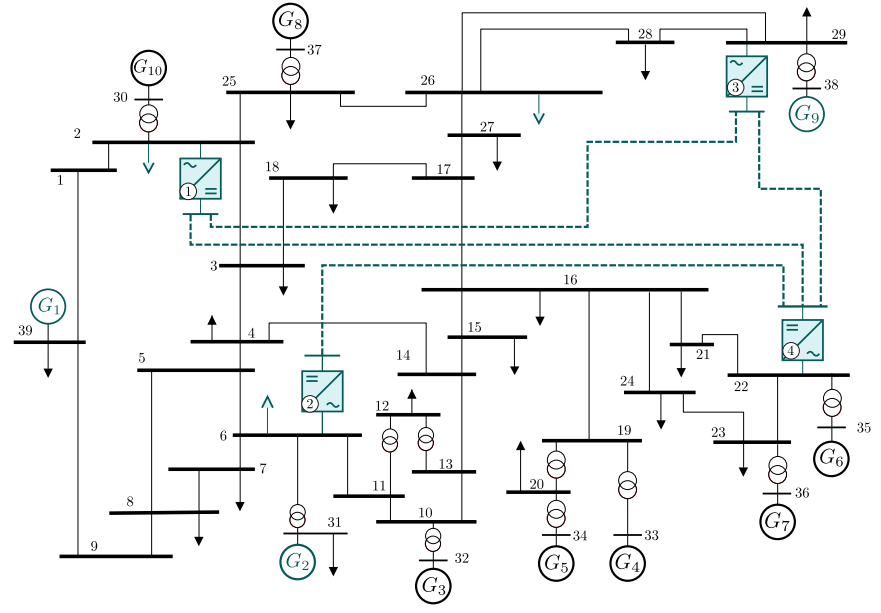

Fig. 4: Modified New England IEEE 39-Bus System

MTDC is composed of $4 \times 600 \mathrm{MW}$ Modular Multilevel Converters. On the AC side, the converters are controlled to track active and reactive power references using classic "vectorcontrol". PI controllers are used to generate the necessary current and voltages references in the $d q$ frame and a Phase Lock Loop is used for tracking the grid voltage angle. The MMC parameters as well as the internal controllers are detailed in [30]. The DC transmission is composed of $4 \times 200 \mathrm{~km}$ cables, their geometrical parameters are the ones in [31]. The DC voltage control strategy is the Voltage Droop control described in [32]. For the described topological situation of the MTDC grid, the location of the converters suggests that their main task is to feed loads 2 and 6 (converters 1 and 2) taking power from generators G9 and G6 (converters 3 and 4). The active and reactive power set-points are summarized in Table III. Besides, the phase voltages at the PCCs (in Table III) of the converters indicate the tendency of the power flow from the west part of the grid to the east part. In this example, for each converter it is allowed to use the full power reserves for transient stability enhancement. Based on the rated power of the converters, the maximum and minimum power variations $\left(\Delta P_{h v d c, k}^{\max }, \Delta P_{h v d c, k}^{\min }\right)$ from the power set-points are computed

\begin{tabular}{|c|c|c|c|c|c|c|}
\hline VSC & $\begin{array}{l}\text { PCC voltage } \\
\text { [p.u. } \angle \text { deg] }\end{array}$ & $\begin{array}{c}\text { Rated power } \\
\text { [MVAR] }\end{array}$ & $\begin{array}{c}P_{h v d c 0, k} \\
\text { [MW] }\end{array}$ & $\begin{array}{c}Q_{h v d c 0, k} \\
\text { [MVAR] }\end{array}$ & $\begin{array}{c}\Delta P_{h v d c, k}^{\max } \\
{[\mathrm{MW}]}\end{array}$ & $\begin{array}{c}\Delta P_{h v d c, k}^{\min } \\
{[\mathrm{MW}]}\end{array}$ \\
\hline 1 & $1.01 \angle 23.4$ & 600 & 400 & 0 & 200 & -1000 \\
\hline 2 & $0.95 \angle 17.4$ & 600 & 400 & 0 & 200 & -1000 \\
\hline 3 & $1.03 \angle 43$ & 600 & -400 & 100 & 1000 & -200 \\
\hline 4 & $1.04 \angle 31.3$ & 600 & -400 & 100 & 1000 & -200 \\
\hline
\end{tabular}
and summarized in Table III.

TABLE III: Parameters of the embedded MTDC.

\section{B. The supplementary controller}

The controller described in Section IV is implemented on the MTDC grid. In Figure 5, a detailed overview of the proposed architecture for the control implementation is illustrated. Figure 5a shows the interactions between: the physical layer - the power system - and the distributed control layer. At the converter location, Local Controllers (LCk) are implemented; they are in charge of computing the active power references. 


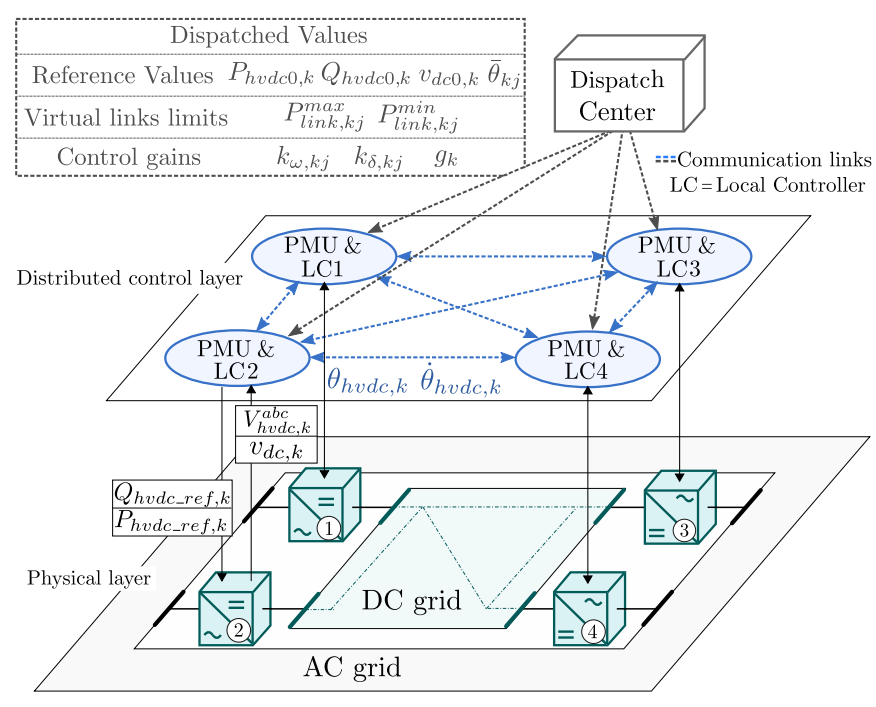

(a) Distributed control architecture

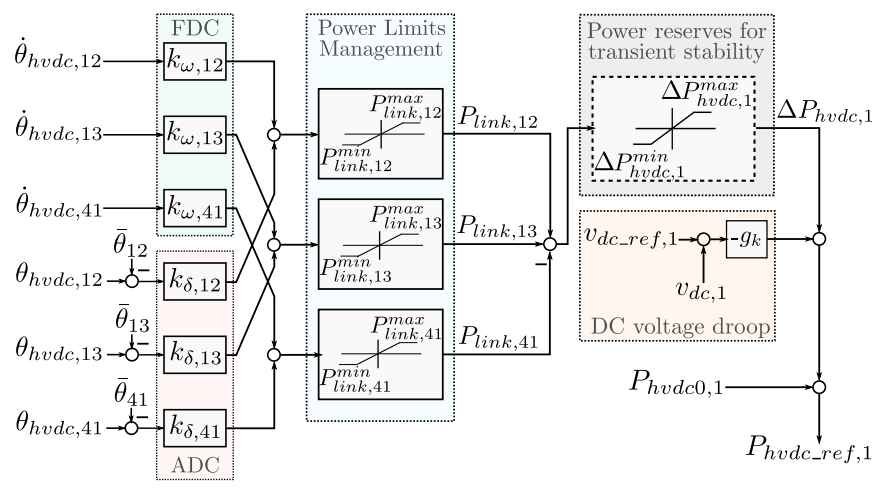

(b) Detailed view of Local Controller 1 LC1

Fig. 5: Implementation of the controller on Station 1

From the physical layer, these controllers take the measurements of $\mathrm{AC}$ and $\mathrm{DC}$ voltages. The $\mathrm{AC}$ voltage measurement is used by the Phasor Measurement Units (PMU) to estimate the PCC's phase angle and frequency, used to compute the control law in Equation (15). The measured DC voltage is used by the voltage droop controller. At the control layer, the Local Controllers (or the PMUs) exchange the values of phase angles and frequencies. The Dispatch Center is in charge of sending to the Local Controllers the power references, the voltage references, the control gains and the virtual link limits.

A detailed view of the Local Control on Station 1 (LC1) is depicted in Figure 5b. The measurements of all the PMUs are used to feed the FDC and the ADC controllers; their generated references are then limited in order to respect the power reserves allocated for transient stability enhancement. Note that these references are limited before the addition of the supplementary active power reference of the voltage droop.

The 4-terminal DC grid gives rise to the possibility to establish 6 pairs of converters, thus 6 virtual links. The 12 virtual links limits are proposed by finding a solution for a system of 12 equations (Equations (30)), which for the studied case is a linear dependent set of equations of rank 8 . The degrees of freedom can be used to arbitrarily set 4 virtual link limits, in order to provide more power reserves to the virtual links with more angular separation in steady state (e.g. virtual link 2-3). The proposed set of gains and limits are summarized in Table IV. For simplicity, the gains of the FDC and ADC controllers are equally set for each virtual link. Although it is preferred to have angle references equal to zero, in this example the angle references are calculated with respect to the initial values in order to compare different control gains in the same initial operating point.

TABLE IV: Gains and limits of the controllers.

\begin{tabular}{cccccc}
\hline $\begin{array}{c}\text { V. Link } \\
k j\end{array}$ & $\begin{array}{c}k_{\omega, k j} \\
{[\mathrm{MW} / \mathrm{Hz}]}\end{array}$ & $\begin{array}{c}k_{\delta, k j} \\
{[\mathrm{MW} / \mathrm{deg}]}\end{array}$ & $\begin{array}{c}\bar{\theta}_{k j} \\
{[\mathrm{deg}]}\end{array}$ & $\begin{array}{c}P_{\text {link,kj }}^{\max } \\
{[\mathrm{MW}]}\end{array}$ & $\begin{array}{c}P_{\text {link,kj}}^{\min } \\
{[\mathrm{MW}]}\end{array}$ \\
\hline $1-2$ & 500 & 20 & 5.92 & 10 & -60 \\
$2-3$ & 500 & 20 & -25.52 & 450 & -100 \\
$3-4$ & 500 & 20 & 11.69 & 40 & -30 \\
$4-1$ & 500 & 20 & 7.89 & 80 & -470 \\
$1-3$ & 500 & 20 & -19.59 & 520 & -60 \\
$2-4$ & 500 & 20 & 13.82 & 490 & -90 \\
\hline
\end{tabular}

\section{Comparison of strategies for a severe three phase fault}

A three-phase fault is applied on line 26-28 near bus 26 and $165 \mathrm{~ms}$ after fault occurrence the line is tripped. The results of the following three control schemes are compared:

- CR: for Constant References. No supplementary control loop is added on the MTDC grid.

- FDC: Only the Frequency Difference Controller (FDC) is implemented with no limitation on the individual virtual link references. Only the total supplementary reference of each converter is limited. This strategy is equivalent to the Weighted Average Frequency in [15].

- FDC-ADC: Frequency Difference Control and the Angle Difference Control are implemented with no limitation on the individual virtual link references. Only the total supplementary reference of each converter is limited.

- FDC-ADC-lim: FDC and ADC are implemented as well as the limitations on each virtual link.

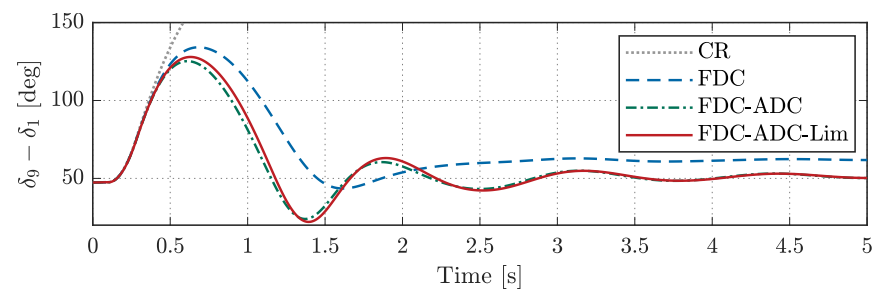

Fig. 6: Rotor angle difference between G9 and G1.

For the given disturbance, the critical generator is G9. Figure 6 shows the rotor angle difference between G9 and G1. The rotor angle difference shows that transient stability is lost if no supplementary control is implemented (CR). All other strategies manage to keep the system in synchronism. During the first swing, the largest rotor deviation is observed when the FDC strategy is used. This can be explained if we examine the power injected by the converters in Figure 7, where it is evident that the control effort is bigger when the ADC control 

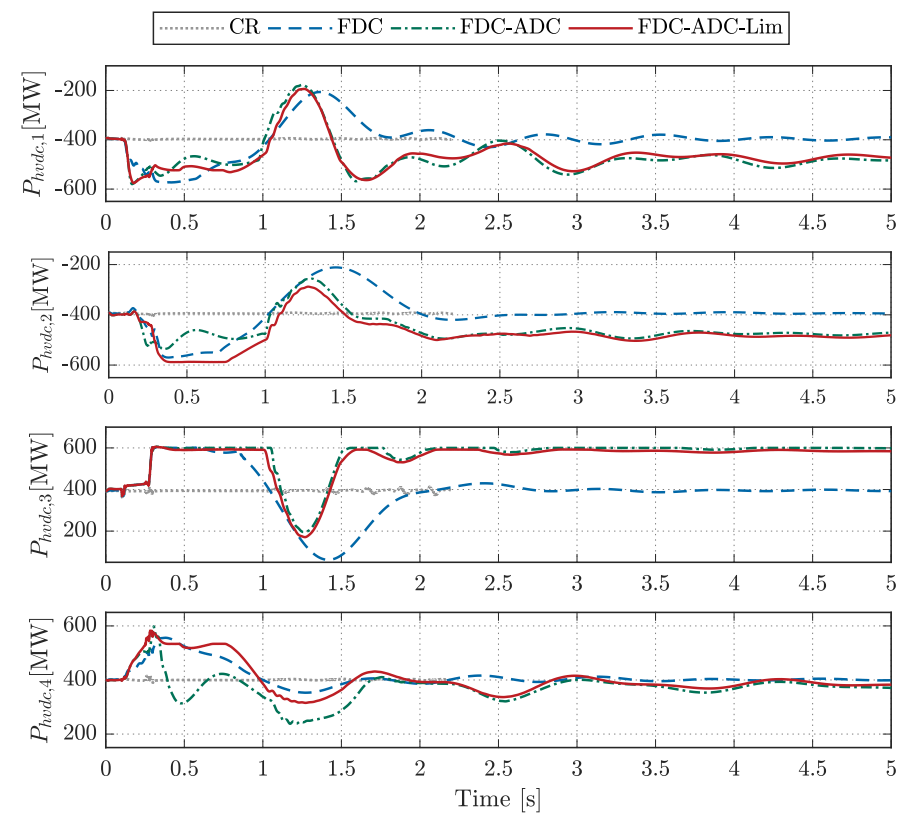

Fig. 7: Active power of Stations

is used. Another important remark is that the angle difference is smaller in the post-fault situation when the ADC is used. it can be also observed that the converters did not get back to its initial operating point, the references are re-dispatched in order to support the static post-fault situation of the AC grid.

The DC voltage at the terminals of the converters is shown in Figure 8. If the FDC strategy is used, when converter 4 saturates (between 0.1s and $0.8 \mathrm{~s}$ ), the DC voltage deviates from its nominal value. However, the FDC strategy does not imply big control efforts, hence those voltage deviations remain between the acceptable limits $( \pm 10 \%$ of the nominal voltage). The FDC-ADC strategy implies bigger control efforts, it can be seen that voltage variations exceed the acceptable limits when converters reach their limits. To handle this problem, the ADCFDC-Lim strategy allows to make the sum of references equal to zero even if the converters reach their limits. When the ADC-FDC-Lim is used, after fault clearance the voltages reach their nominal values smoothly. As it can be seen, converters 1 and 4 stop their control actions when converters 2 and 3 (between $0.2 \mathrm{~s}$ and $0.7 \mathrm{~s}$ ) reach their limits. If FDC-ADC is adopted, converters 1 and 4 continue injecting power, which discharges the DC grid. In Figure 9, it is shown that during this time span (between $0.2 \mathrm{~s}$ and $0.7 \mathrm{~s}$ ) every virtual link is saturated, impeding the power references to move.

Figure 10 shows the evolution of the voltage phase difference between each pair of converters when the FDC and the FDC-ADC-Lim strategies are implemented. The first difference that is observed is that during the first swing, angle differences are higher when the FDC strategy is used. Besides, when the FDC-ADC-Lim strategy is adopted, all post-fault angle differences are closer to their pre-fault values, meaning that adjacent AC lines are less charged. The FDC-ADC-Lim strategy makes angles to be less separated in the post fault state, which indicates a globally less stressed AC system.
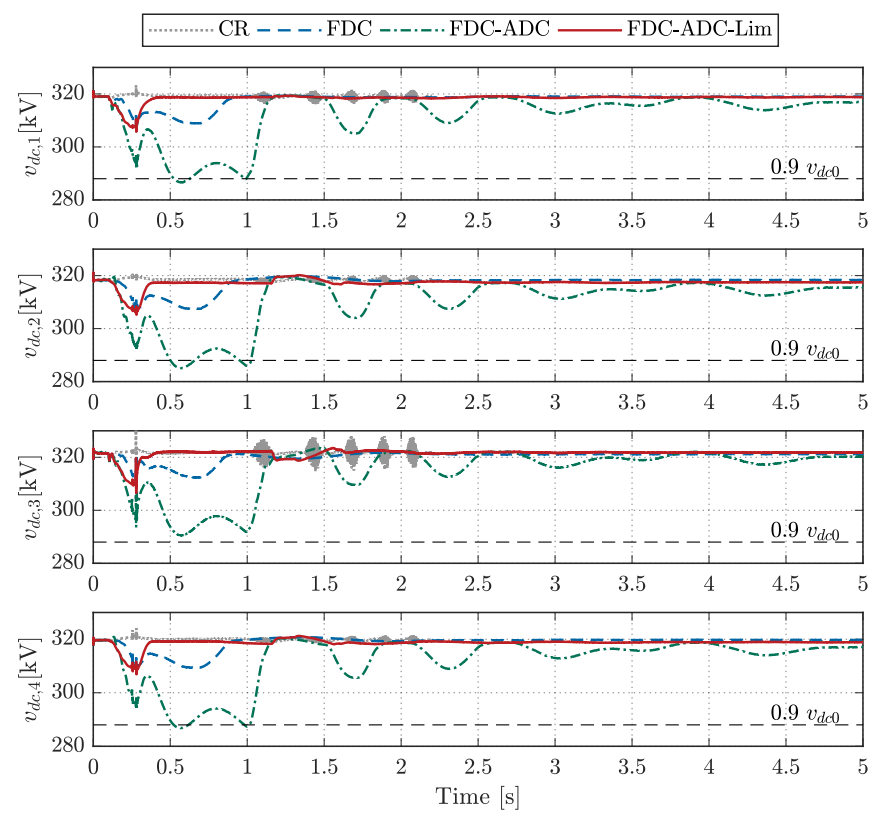

Fig. 8: DC voltage of Stations

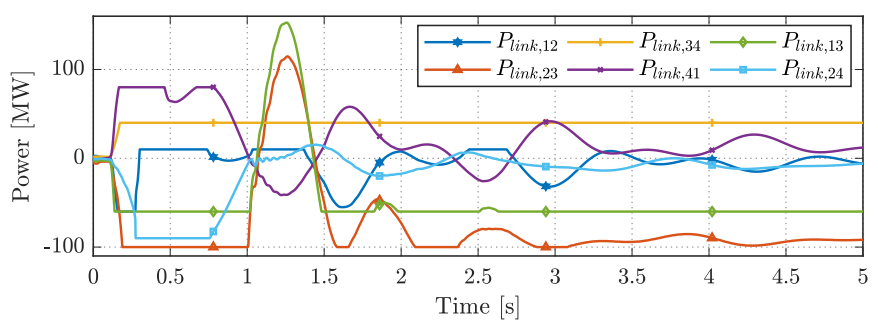

Fig. 9: References of the Virtual Links for FDC-ADC-Lim

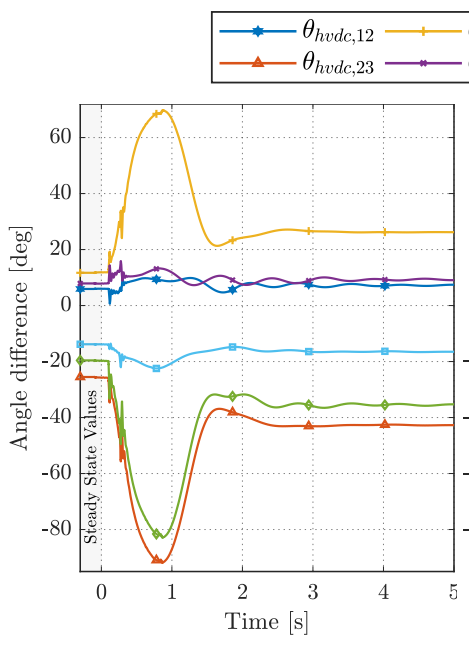

(b) FDC
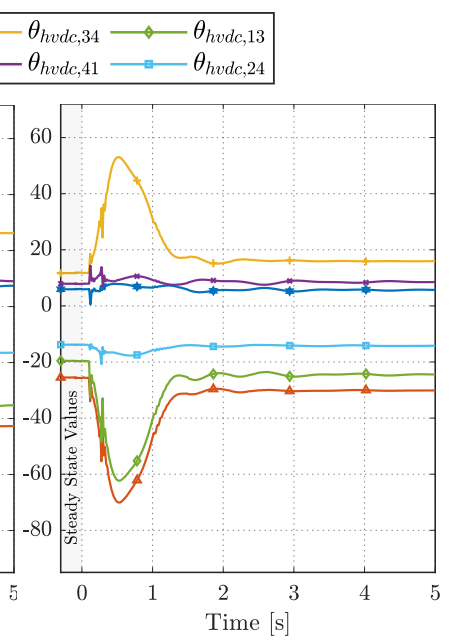

(c) FDC-ADC-Lim
Fig. 10: Angle differences between each pair of converters

\section{Critical Clearing Times}

For quantifying the performance of the control, the Critical Clearing Times (CCT $\pm 1 \mathrm{~ms})$ are found for three-phase faults at different locations. The FDC-ADC strategy is not contemplated since for all cases, DC voltages deviate beyond the $\pm 10 \%$ limit. The results are summarized in Table V. 
TABLE V: Critical clearing times for different faults.

\begin{tabular}{|c|c|c|c|c|c|c|}
\hline \multirow{2}{*}{ Fault } & \multirow{2}{*}{ Bus } & \multirow{2}{*}{ Tripped line } & \multicolumn{4}{|c|}{$\mathrm{CCT}[\mathrm{ms}]$} \\
\hline & & & $\overline{\mathrm{CR}}$ & FDC & FDC-ADC-lim & Delay $60 \mathrm{~ms}$ \\
\hline 1 & 26 & $26-28$ & 132 & 189 & 193 & 189 \\
\hline 2 & 14 & $14-15$ & 246 & 249 & 277 & 260 \\
\hline 3 & 24 & $23-24$ & 205 & 216 & 219 & 218 \\
\hline 4 & 4 & $3-4$ & 216 & 220 & 230 & 227 \\
\hline 5 & 17 & $17-27$ & 232 & 251 & 254 & 252 \\
\hline 6 & 14 & $4-14$ & 252 & 258 & 293 & 292 \\
\hline
\end{tabular}

Clearly, the transient stability margins have been increased by the use of supplementary controllers for the tested cases. When the fault occurs near the VSC stations (cases 1, 3 \& 5), both supplementary controls are almost equally effective. Since the measured frequency at the converter's PPC deviates rapidly, both strategies saturate the converters during the first swing providing similar responses. In the other hand, when the fault occurs in the central part of the grid (faults $2,4 \& 6$ ), the FDC-ADC-lim strategy is found to be more effective. This is due to the fact that the frequency deviations measured at PCCs are smaller, leading to less severe control actions when the FDC is implemented. The measured angle deviations cause the FDC-ADC-lim strategy to compute more aggressive control actions. In addition, the ADC part of the control acts as an "AC network reinforcing" the grid and providing a more stable post-fault equilibrium point. The impact of the communication latency, inherent to any WAMS, is analyzed by introducing a delay of 60ms in the control [33]. The CCTs when the FDCADC-Lim strategy is implemented including communication delays are reported in the last column of Table V. These results indicate that the negative effect of the communication latency on stability is small; a fact that is consistent with the conclusions in [13], [20], [34].

\section{E. Impact of control parameters}

From the analysis in section IV-B, especially from Equations (23) and (29), it is clear that the stability is affected by the control gains. Theoretically, higher gains will produce larger stability margins of the AC system. In addition, by using the proposed coordination of the limits, high control gains can be applied without risking the DC voltage stability. The CCTs for the same 6 fault locations are calculated when the FDC-ADCLim strategy is implemented using different control gains. The values of the gains as well as the corresponding CCTs are summarized in Table V-E. For all set of gains, the limits of the Virtual Links remain the same as presented in Table IV and the communication delays are neglected.

TABLE VI: Critical clearing times for different control gains

\begin{tabular}{ccccccccc}
\hline & \multicolumn{3}{c}{ FDC-ADC-lim } & \multicolumn{6}{c}{ CCT[ms] } \\
\hline Gains set & $k_{\omega, k j}$ & $k_{\delta, k j}$ & \multicolumn{1}{c}{ Fault case } \\
& {$[\mathrm{MW} / \mathrm{Hz}]$} & {$[\mathrm{MW} / \mathrm{deg}]$} & 1 & 2 & 3 & 4 & 5 & 6 \\
\hline 1 & 500 & 20 & 193 & 277 & 219 & 230 & 254 & 288 \\
2 & 1000 & 20 & 195 & 286 & 222 & 250 & 258 & 293 \\
3 & 500 & 40 & 195 & 283 & 220 & 252 & 256 & 298 \\
4 & 1000 & 40 & 195 & 288 & 223 & 260 & 258 & 300 \\
\hline
\end{tabular}

Regarding the faults near the converter stations $(1,3 \& 5)$, the results indicate that higher gains have almost no impact on the CCT. As stated in the previous subsection, these faults already lead to the saturation of the converters using the set 1 of gains, thus higher gains show similar results. Concerning the faults in the central part of the grid, higher control gains lead to higher CCT values (sets 2 and 3 with respect to 1). However, doubling the control gains (in Set 4 with respect to Set 1), has approximately the same impact as sets 2 and 3 .

It is noteworthy, that higher gains of the $\operatorname{ADC}\left(k_{\delta}\right)$ can lead to a less stressed post-fault situation (as in Figure 6), however as observed on the time domain simulation, the ADC part of the control is prone to reduce the damping of some oscillating modes (as also explained in [18]), this is why higher gains of the FDC are recommended. Using the proposed coordination of actuator limits, very high gains can be adopted, a bang-bang alike strategy as in [13] can be implemented, although this time in a distributed manner. However, the high gains could lead to the amplification of PMU noise (especially in converters connected to weak grids), therefore a trade-off is to be found. As a further way to achieve better results, the proposed strategy can be combined with reactive power modulations, e.g. those proposed in [20], [34]).

As a final remark, in a practical application it is recommended to set the active power and angle references to zero (i.e. $\overline{\boldsymbol{\theta}}=0$ and $\boldsymbol{P}_{\boldsymbol{h v d c 0}}=0$ ). By using these values:

- The ADC sets the steady-state value of the MTDC active power references at all moments. No need for the TSO to manually set the power references.

- The MTDC grid will follow the natural AC active powerflow pattern. Forced active power loop-flows on the adjacent AC lines are avoided.

- There is no need of the TSO to periodically re-dispatch reference values, virtual link limits or even control gains.

\section{Conclusions}

In this article, a control strategy for MTDC grids to improve the rotor angle stability of the power system is presented. The strategy is based on the principle of virtual links injecting damping and synchronizing power, using as feedback frequencies and angles at the points of common coupling of the converters. The following conclusions can be drawn:

- Compared with an "equivalent" pure AC grid, a hybrid AC/DC grid might have lower transient stability margins if no supplementary references are used. This is due to the natural synchronizing power injections of the AC lines.

- Through the proposed control, damping (Frequency Difference Control - FDC) and synchronizing (Angle difference control - ADC) power is injected between every pair of converters. The ADC modifies the potential energy of the AC system while the FDC acts on its energy dissipation. To reach this conclusion, a Lyapunov function has been proposed for the closed loop system.

- By matching the control actions of each pair of stations (virtual link concept), it is possible to assure the zero DC power imbalance and make the supplementary reference to respect the power limits of converters.

- Via the ADC, the references of the converters can be automatically re-dispatched allowing to follow the AC 
transmission pattern like a set of $\mathrm{AC}$ lines, thus reducing the stress of the surrounding $\mathrm{AC}$ system. If power and angle references are set to zero (i.e. $\overline{\boldsymbol{\theta}}=0$ and $\left.\boldsymbol{P}_{\boldsymbol{h v d c 0}}=0\right)$ forced active power loop-flows in the AC lines surrounding the MTDC grid are avoided.

- The FDC-ADC-Lim strategy gathers the advantages of the ADC and FDC while reducing the impact of large active power modulations on the DC voltage.

\section{REFERENCES}

[1] ENTSO-E, "HVDC Links in System Operations," ENTSO-E, Brussels, BE, Technical paper, 2019.

[2] N. Hatziargyriou, J. Milanović, C. Rahmann, V. Ajjarapu, C. Cañizares, I. Erlich, D. Hill, I. Hiskens, I. Kamwa, B. Pal et al., "Stability definitions and characterization of dynamic behavior in systems with high penetration of power electronic interfaced technologies," IEEE Power \& Energy Society, Tech. Rep., 2020.

[3] H. Wu and X. Wang, "Design-oriented transient stability analysis of PLL-synchronized voltage-source converters," IEEE Transactions on Power Electronics, vol. 35, no. 4, pp. 3573-3589, 2019.

[4] — , "Design-oriented transient stability analysis of grid-connected converters with power synchronization control," IEEE Transactions on Industrial Electronics, vol. 66, no. 8, pp. 6473-6482, 2018.

[5] H. Yu, M. Awal, H. Tu, I. Husain, and S. Lukic, "Comparative Transient Stability Assessment of Droop and Dispatchable Virtual Oscillator Controlled Grid-Connected Inverters," IEEE Transactions on Power Electronics, 2020.

[6] D. Pan, X. Wang, F. Liu, and R. Shi, "Transient stability of voltagesource converters with grid-forming control: A design-oriented study," IEEE Journal of Emerging and Selected Topics in Power Electronics, vol. 8, no. 2, pp. 1019-1033, 2019

[7] T. Smed and G. Andersson, "Utilizing HVDC to damp power oscillations," IEEE Transactions on Power Delivery, vol. 8, no. 2, pp. 620-627, 1993.

[8] H. F. Latorre, M. Ghandhari, and L. Söder, "Active and reactive power control of a VSC-HVDC," Electric Power Systems Research, vol. 78, no. 10 , pp. 1756-1763, 2008.

[9] J. C. Gonzalez-Torres, G. Damm, V. Costan, A. Benchaib, and F. Lamnabhi-Lagarrigue, "Transient stability of power systems with embedded VSC-HVDC links: Stability margins analysis and Control," IET Generation, Transmission \& Distribution, 2020.

[10] J. J. Dougherty and H. Kirkham, "System aspects of a tapped DC line with dynamic controls," IEEE Transactions on Power Apparatus and Systems, no. 8, pp. 2066-2074, 1970.

[11] M. Rahman and P. Dash, "Stabilization of an AC-DC power system using a controlled multiterminal HVDC link," Electric Power Systems Research, vol. 4, no. 2, pp. 135-146, 1981.

[12] J. Machowski, P. Kacejko, Ł. Nogal, and M. Wancerz, "Power system stability enhancement by WAMS-based supplementary control of multiterminal HVDC networks," Control Engineering Practice, vol. 21, no. 5, pp. 583-592, 2013.

[13] R. Eriksson, "Coordinated control of multiterminal DC grid power injections for improved rotor-angle stability based on Lyapunov theory," IEEE Transactions on Power Delivery, vol. 29, no. 4, pp. 1789-1797, 2014.

[14] G. Tang, Z. Xu, H. Dong, and Q. Xu, "Sliding mode robust control based active-power modulation of multi-terminal HVDC transmissions," IEEE Transactions on Power Systems, vol. 31, no. 2, pp. 1614-1623, 2016.

[15] J. Renedo, A. Garcia-Cerrada, and L. Rouco, "Active power control strategies for transient stability enhancement of AC/DC grids with VSCHVDC multi-terminal systems," IEEE Transactions on Power Systems, vol. 31, no. 6, pp. 4595-4604, 2016.

[16] J. Renedo, A. García-Cerrada, and L. Rouco, "Reactive-power coordination in VSC-HVDC multi-terminal systems for transient stability improvement," IEEE Transactions on Power Systems, vol. 32, no. 5, pp. 3758-3767, 2017.

[17] J. Renedo, L. Rouco, A. García-Cerrada, and L. Sigrist, "A communication-free reactive-power control strategy in vsc-hvdc multiterminal systems to improve transient stability," Electric Power Systems Research, vol. 174, p. 105854, 2019.

[18] L. Coronado, C. Longas, R. Rivas, S. Sanz, J. Bola, P. Junco, and G. Perez, "Inelfe: Main description and operational experience over three years in service," in 2019 AEIT HVDC International Conference (AEIT $H V D C$ ). IEEE, 2019, pp. 1-6.
[19] M. A. Pai, Energy function analysis for power system stability. New York, United States: Springer Science \& Business Media, 2012.

[20] X. Fan, J. Shu, and B. Zhang, "Coordinated control of DC grid and offshore wind farms to improve rotor-angle stability," IEEE Transactions on Power Systems, vol. 33, no. 4, pp. 4625-4633, 2018.

[21] A. Zama, A. Benchaib, S. Bacha, D. Frey, and S. Silvant, "High dynamics control for MMC based on exact discrete-time model with experimental validation," IEEE Transactions on Power Delivery, vol. 33, no. 1,2018

[22] I. González-Torres, H. Miranda-Vidales, J. Espinoza, C.-F. MéndezBarrios, and M. González, "State feedback control assisted by a gain scheduling scheme for three-level NPC VSC-HVDC transmission systems," Electric Power Systems Research, vol. 157, pp. 227-237, 2018.

[23] L. Harnefors, F. M. M. Rahman, M. Hinkkanen, and M. Routimo, "Reference-feedforward power-synchronization control," IEEE Transactions on Power Electronics, vol. 35, no. 9, pp. 8878-8881, 2020.

[24] H.-D. Chiang, Direct methods for stability analysis of electric power systems: theoretical foundation, BCU methodologies, and applications. Hoboken, New Jersey, US: John Wiley \& Sons, 2011.

[25] H. D. Chiang and J. S. Thorp, "The closest unstable equilibrium point method for power system dynamic security assessment," IEEE Transactions on Circuits and Systems, vol. 36, no. 9, pp. 1187-1200, 1989.

[26] I. A. Calle, P. Ledesma, and E. D. Castronuovo, "Advanced application of transient stability constrained-optimal power flow to a transmission system including an hvdc-lcc link," IET Generation, Transmission \& Distribution, vol. 9, no. 13, pp. 1765-1772, 2015.

[27] L. Liu, Z. Hu, R. Ye, Z. Lin, X. Yang, and Y. Yi, "Study on emergency power control strategy for ac/dc hybrid power system containing vschvdc," in AIP Conference Proceedings, vol. 1955, no. 1. AIP Publishing LLC, 2018, p. 040105.

[28] J. C. Gonzalez-Torres, V. Costan, G. Damm, A. Benchaib, F. LamnabhiLagarrigue, and B. Luscan, "Procédé de commande d'un lien de transmission électrique incluant une ligne haute tension continu," French Patent WO2 019174 999A1, Mar., 2018.

[29] H. F. Latorre, M. Ghandhari, and L. Soder, "Application of Control Lyapunov Functions to Voltage Source Converters-based High Voltage Direct Current for Improving Transient Stability," in Proc. 2007 IEEE Lausanne Power Tech, Lausanne, Switzerland, 2007, pp. 244-249.

[30] K. Shinoda and A. Benchaib and J. Dai and X. Guillaud, "Virtual capacitor control: mitigation of DC voltage fluctuations in MMC-Based HVDC Systems," IEEE Transactions on Power Delivery, vol. 33, no. 1, pp. $455-465,2017$.

[31] D. Loume, M. N. Tuan, A. Bertinato, and B. Raison, "DC cable modelling and High Voltage Direct Current grid grounding system," in Proc. 9th Int. Conf. Insul. Power Cables, 2015, pp. 1-6.

[32] K. Shinoda, A. Benchaib, J. Dai, and X. Guillaud, "DC voltage control of MMC-based HVDC grid with Virtual Capacitor Control," in Proc. 2017 19th European Conference on Power Electronics and Applications (EPE'17 ECCE Europe), 2017, pp. P.1-P.10.

[33] Y. Cui, R. G. Kavasseri, and N. R. Chaudhuri, "Modeling and simulation of dynamic communication latency and data aggregation for wide-area applications," in Proc. 2016 Workshop on Modeling and Simulation of Cyber-Physical Energy Systems (MSCPES). IEEE, 2016, pp. 1-6.

[34] J. Renedo, A. García-Cerrada, L. Rouco, and L. Sigrist, "Coordinated Control in VSC-HVDC Multi-Terminal Systems to Improve Transient Stability: The Impact of Communication Latency," Energies, vol. 12, no. 19 , p. $3638,2019$.

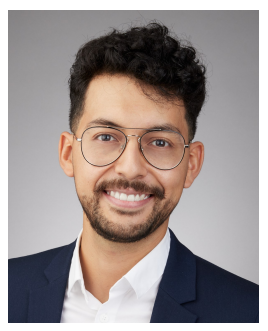

Juan Carlos Gonzalez-Torres received both the Electromechanical Engineering degree from Universidad Autonoma de San Luis Potosi and the Master of Engineering from Ecole Centrale de Lille in 2014. He graduated with a Master of Science degree from ParisTech (The Paris Institute of Technology) in 2015. In 2019, he obtained the Ph.D. in Automatic Control from Paris-Saclay University. He has been working as a research engineer at Supergrid Institute since 2016, where he is part of the Architecture \& Systems program. His main research interests include modeling and control of power systems, HVDC transmission systems and integration of renewable energies via power electronics-based devices. 


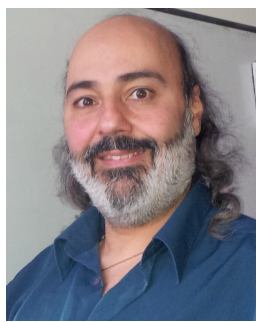

Gilney Damm is Associate Professor at the ParisSaclay University, at the Laboratory L2S, France. He received his Habilitation à Diriger des Recherches in 2010 at Evry University; his Ph.D. at the Supelec/Université Paris Sud in 2001; his M.Sc. at COPPE-Rio de Janeiro Federal University (UFRJ) in 1997 and his Bachelor in Electronic Engineer at the UFRJ in February 1995. His main research interests concern the nonlinear control of power systems (SmartGrids-SuperGrid-MicroGrids). Applications are in the field of large scale renewable energy integration; Multi-Terminal HVDC systems; Variable Speed Pumped Storage Plants; mixed AC/DC Grids; SmartCities and SmartGrids; control of power generators (transient stabilization, frequency and voltage stability, synthetic inertia); synchronization of power networks; MicroGrids. He is currently partner of the Energy Transition Institute (ITE) Efficacity, where he is leading scientist of the Urban SmartGrids pole. He is also partner of the ITE SuperGrid. He is co-leader of the French research forum on SmartGrids, subtopic leaderon the France-Singapour network on SmartGrids and partner of the International Associated Laboratory (LIA-CNRS) SmartGrids with Canada and PowerGrids with Brazil. He is member of the IFAC Technical Committee TC 6.3 Power and Energy Systems and Associated Editor of the European Journal of Control and the journal Energies.

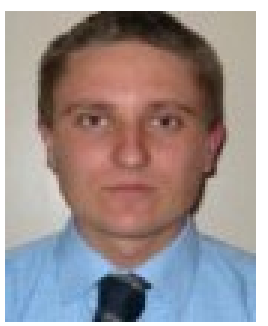

Valentin Costan received the Ph.D. degree from the Institut National Polytechnique de Toulouse, in 2007. He joined EDF R\&D in 2009 as Research Engineer. His research activities focus on the stability analyses of power systems with synchronous machines and power electronics based devices.

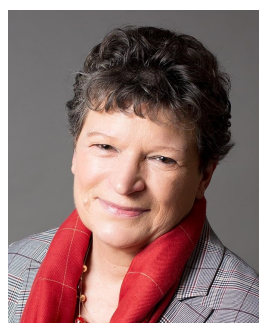

Françoise Lamnabhi-Lagarrigue, IFAC Fellow, is CNRS Distinguished Research Fellow, at the Laboratoire des Signaux et Systèmes. She obtained the Master of Mathematics degree at the University Paul Sabatier (Toulouse) in 1976 and she held a CNRS researcher position in 1980. She received her $\mathrm{Ph} . \mathrm{D}$. and Habilitation Doctorate degrees from the University Paris Sud in 1980 and 1985, respectively. She has been Scientific Manager of the Marie Curie Control Training Site and of the HYCON and HYCON2 Networks of Excellence. She is the founder of the European Embedded Control Institute (EECI) and has been the chair of the EECI International Graduate School on Control. She was serving as nominated Member of the IFAC Technical Board, and as elected or nominated Member of the Board of Governors of the IEEE Control Systems Society. She has been deputy director of the Doctoral School STIC of the University of ParisSaclay. She was appointed member of the Scientific Council of the Institute for Information Science and interactions. She was a member of the Programme Committee of the ITE SuperGrid. Her main research interests include observer design, performance and robustness issues in nonlinear, hybrid, networked and distributed control systems. She is Senior Area Editor of International Journal of Control and Editor-in-Chief of Annual Reviews in Control. She is the prizewinner of the 2008 Michel Monpetit prize of the French Academy of Science and the 2019 Irène Joliot-Curie prize, Woman Scientist of the Year. She is a knight of the Legion of Honor.

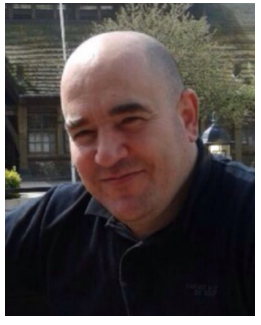

Abdelkrim Benchaib received his $\mathrm{PhD}$ from the Automatic Systems Laboratory, Picardie University, France, in December 1998 and in 2014 his HDR (French post-doctoral degree allowing its holder to supervise PhD students)" from Paris-Orsay University. He joined Alstom in July 2000 where he has been working as a power quality and smart grid project leader and now he is with GE Grid solutions. Abdelkrim is working with the SuperGrid institute where he is an $R \& D$ group manager for real-time strategies for super grids control and dispatch. His expertise and research interests include automatic control, AC and DC power systems and power electronics. Abdelkrim BENCHAIB is associate Professor at the Cnam (Conservatoire National des Arts et Métiers) teaching wind energy and power network. He has been General Chairman of the EPE 2020 ECCE Europe Conference. 